\title{
Research on Management Accounting Teaching Based on Cloud Accounting System under Big Data Background
}

\author{
Yangyang Li \\ Yunnan Technology and Business University, Kunming, Yunnan, 651700
}

Keywords: big data; cloud accounting system; management accounting teaching; opportunity

\begin{abstract}
With the advent of the era of big data, the market economy has also developed rapidly under the cumulative growth of data. All circles of society have begun to pay close attention to the problem of big data. In the era of big data and cloud computing, management accounting is also facing new opportunities and challenges. This paper introduces the concept of big data and cloud computing and their great role in management accounting, and points out the opportunities and challenges faced by management accounting teaching in the era of big data. On this basis, the paper points out how to effectively integrate management accounting and cloud accounting system based on big teaching background, so as to promote the rapid development of management accounting teaching.
\end{abstract}

\section{Introduction}

Early management accounting mainly serves for internal management decisions, with emphasis on cost accounting and investment return analysis, standard cost management and annual budgeting. The early management accounting education is mainly based on the cost accounting and the teaching content. Johnson pointed out that the development of traditional management accounting is lagging behind. The theory of management accounting has been unable to adapt to the trend of technological innovation and globalization in the information age [1]. Cloud computing and large data processing are the advanced computer technology, which have been widely used. Financial data is the core of enterprise management and development, and enterprise financial information management has always been one of the important works of enterprise information management [2]. Traditional enterprise financial information management only carries out automation and process transformation to the financial management process, and can not make full use of the accumulated financial data in the development process of enterprises and find loopholes or problems in the operation and management of enterprises [3-4]. Therefore, the financial data of the running information under the background of big data to cloud accounting management accounting teaching system based on the full collection of the foundation, the implementation of intelligent mining and processing, discover the existence of enterprise financial operation, optimize enterprise financial management process, this study has important significance.

\section{The meaning, characteristics and function of big data}

\subsection{The meaning of big data}

With the emergence of cloud computing and the wide application of mobile Internet, large data has developed rapidly. Big data and big data or data, it is a set of large quantity, complex structure, many types of data is composed of data, data processing and application model based on cloud computing, through data integration and sharing, the formation of various information resources can provide help to the use of cross enterprise management [5].

\subsection{Characteristics of big data}

According to the point of view of western scholars, the characteristics of large data can be summed up into "4V", that is "volume", "variety", "velocity” and "value”. 
First of all, the amount of data is huge. Data amount TB level, jump to the PB level, and from various aspects; secondly, the diversity of data types. Such as documents, audio, log, location information and so on, the data comes from a variety of channels; again, the processing speed is fast. It is usually required to give analysis results in a very short period of time, and too long analysis time will make it lose its use. This feature is also the biggest difference between large data processing technology and traditional data mining technology [6]. Finally, the value density is low, and the high value of business information can be quickly obtained from a large number of data. Therefore, according to the characteristics of big data, the effective use of cloud computing for data collection, processing, analysis, mining and proper use is becoming an important way for modern management accounting to play a role and create more opportunities for development and business value for enterprises.

\subsection{The role of big data in management accounting}

First of all, large amount of large data for the enterprise to carry out management accounting work, to obtain enterprise comprehensive information provides an important resource base and support.

Secondly, the rapid circulation of data can promote the efficiency of business management. The database established by the enterprise to realize mass storage and analysis and mining can realize the timely and rapid processing of the collected data [7]. It will help enterprises to provide real time management reports and improve the efficiency and effectiveness of accounting work.

Finally, timeliness data can create value for the enterprise. Quickly collected data put forward higher requirements for the management of accounting work, enterprises must adopt the corresponding data analysis techniques to achieve the extraction of valuable commercial information from massive data, and quick analysis mining, in order to achieve the enterprise management goal, to create more value for the enterprise.

\section{The application mode of financial cloud accounting system}

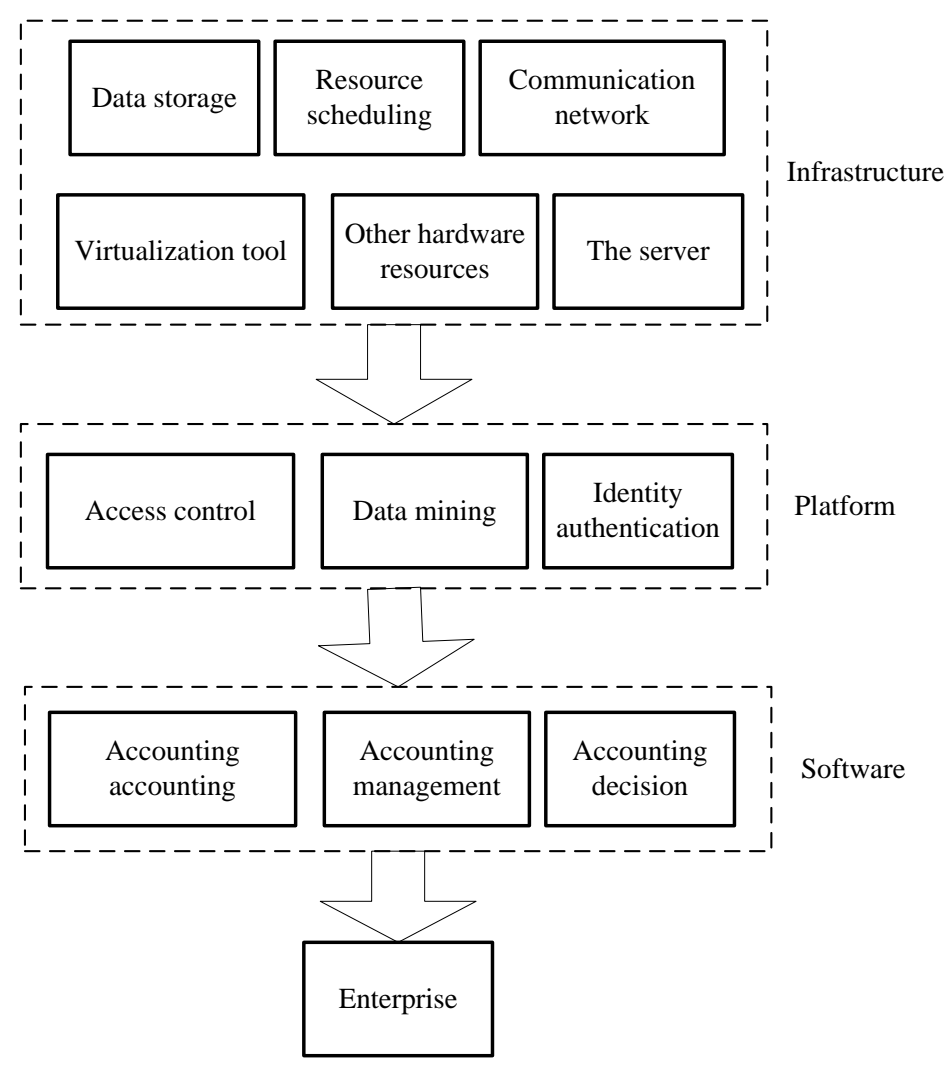

Figure 1. The application mode of financial cloud accounting system

Under the background of big data, enterprise financial cloud accounting system can access the 
resource pool through the Internet to get the needed application services according to the IT hardware and software resources provided by the service providers. Cloud accounting system can connect and integrate a large number of computer processing nodes, take distributed application mode to form a large accounting operation cent and provide high-speed financial business processing, cloud data access and storage services to users [8]. At present, the common mode of enterprise finance cloud accounting system mainly includes three kinds of infrastructure, namely, infrastructure service, platform, service and software, as well as software, as well as service, as shown in figure 1.

Infrastructure as a service cloud is located in the bottom of the accounting system, can be integrated database storage, Web application server, PC server and other hardware resources, the use of distributed computing, virtualization technology to expand the capacity of the hardware resources, be provided to all enterprises, users can work in different periods or stages. The platform is located in the middle layer of the cloud accounting system, which provides a basic platform for users and does not provide logical business applications. Users can deploy and build accounting business processing system according to business accounting and other business processing needs, so that they can make selective customization according to needs and provide users with creative value platform services. Software as a service is used to build accounting cloud services such as accounting, accounting management, accounting decisions and so on. Based on the infrastructure and platform, it provides users with a completely new application mode of software and hardware. Compared with the traditional mode of cloud accounting services, relying on modern cloud computing, distributed computing, Internet and virtual technology, can provide a powerful online service function for enterprise accounting system, enterprises do not need to invest a lot of hardware and software, professional personnel and other funds, without the need for operation management and maintenance of any cloud, accounting system application services can be purchased.

\section{The countermeasures for the teaching of management accounting in the age of big data and cloud computing}

\subsection{Establishing the management accounting theory system with Chinese characteristics}

In 2014, the Ministry of Finance issued the guiding opinions on comprehensively promoting the construction of management accounting system, and put forward the importance and necessity of comprehensively promoting the construction of management accounting system. We should not copy the western management accounting theory [9-10]. We should explore the management accounting theory suitable for China's actual conditions according to the actual conditions of our country, and develop a complete set of management accounting system with Chinese characteristics.

In order to support and promote the formation of the management accounting system, we should integrate the resources with advantages in universities or enterprises. At the same time, colleges and universities should establish scientific research bases, organize personnel to carry out theoretical research and case study, and summarize experience in practice [11]. We also need to increase the reward mechanism for management accounting research results, and encourage more talents to study management accounting through incentive mechanism, so as to promote the development of management accounting in China.

\subsection{Grasp the wave of big data and establish the consciousness of applying management accounting in big data}

The development of management accounting, under the wave of big data, also needs to be supported by new technology to improve the management efficiency. In recent years, the development of cloud computing, large data, mobile Internet and so on, enterprises must grasp the situation and seize the opportunity [12]. For management accounting, the opening and sharing of information resources provides more convenience for its application. At the same time, to better realize the value of management accounting in the development of enterprises, to explore the value of its resources from massive data, and real-time integration analysis, therefore, all parties need to 
make joint efforts for the development of management accounting to add strength. Facing the coming of the era of big data, we must seize the opportunity of developing and upgrading and face the challenges. First of all, we need to enhance the importance of strengthening the role of management accounting in the era of big data. Accounting theorists and relevant research institutions should combine western management accounting theory with the actual situation of China in a timely manner, and summarize and summarize the practical experience of management accounting related to big data [13]. The related research results timely push out through conferences, books, newspapers and other forms, and can integrate the related knowledge of big data in the management of accounting professional education and personnel training, in order to promote the application of big data in China in management accounting more in-depth. The impact of cloud computing and mobile technology on the teaching of management accounting is shown in table 1.

Table 1 . The influence of cloud computing and mobile technology on the teaching of management accounting

\begin{tabular}{|c|c|}
\hline Advantage & $\begin{array}{l}\text { Scale, cost reduction, cooperative environment (with customers and } \\
\text { employees) without borders, data backup and recovery }\end{array}$ \\
\hline Inferiority & $\begin{array}{c}\text { Service protocols, lack of standards for Internet connections, integration } \\
\text { between cloud providers and existing architectures, and difficulties in data } \\
\text { migration }\end{array}$ \\
\hline Oppo & $\begin{array}{l}\text { ERP-SaaS, mobile automation, accounting documents, data collection, } \\
\text { safety improvement }\end{array}$ \\
\hline Challenge & $\begin{array}{c}\text { Accounting and financial data loss, privacy violations, system practicality, } \\
\text { dissatisfaction with product / performance, supplier pricing power, legal } \\
\text { and regulatory constraints }\end{array}$ \\
\hline
\end{tabular}

As the managers of the company, but also attach importance to the big data technology to the great role of management accounting work in management decision-making, actively study the use of big data technology in management accounting knowledge, and promote grassroots staff awareness of big data and the corresponding training. It can directly compare the changes of big data before and after management accounting work and analyze its great driving force for business management, so as to enhance the management of enterprises and enhance the performance and performance of employees.

\subsection{Setting up the idea of management accounting and paying attention to the training of management accounting talents with large data knowledge}

If managers want to better play the role of management accounting in the decision-making of enterprises, we must set up management concepts, especially the concept of management accounting under the background of big data. Distinguish between the management accounting and the traditional accounting, clear the important position of the management accounting in the enterprise management, and better play the role of the management accounting. At the same time, enterprises should make up not only master big data knowledge and interdisciplinary professionals know the management accounting gap, take the initiative to improve enterprise applications for large data analysis, processing, mining ability value information, promote the innovation and development of the entire enterprise management mode, improve business performance, and better services for the development of enterprises.

\subsection{Building an accounting information platform based on cloud computing}

Under the era of big data collected data requires efficient enough storage space, and can achieve a large number of diverse, rapid and timely data processing and analysis, which is capable of rapid response, providing low latency and valuable information, help enterprises to make timely decisions. With the emergence of new technology, information processing capability is improved, such as cloud computing, cloud platform and so on. Dynamic, scalable, virtualized resources provided by the Internet, enterprises can better finish on the vast variety of complex data storage, processing, analysis, mining, which can not only improve the efficiency of enterprises, but also can realize the 
value of the depth of data mining, its value is fully used. Therefore, the construction of the accounting information management system based on cloud computing is the most convenient method to solve the problem of large data storage and analysis processing.

\section{Conclusions}

In the era of big data, the explosive growth of information has brought great convenience to our life, and it also provides a favourable environment for the development of enterprises. At the same time, the change of external environment brings new challenges to the traditional management mode of enterprises. The lagging behind management accounting is faced with opportunities and challenges. Big data has provided a larger platform for the effective and in-depth development of management accounting, which has made great changes in traditional management accounting concepts. The rapid development of big data has promoted the continuous development of management accounting. In the wave of big data, enterprises must seize the opportunity for development of management accounting, grasp the situation of the country actively the development of management accounting, deal with big data difficulties and challenges, to achieve their own development across, and management accounting will enter a new stage of rapid development.

\section{References}

[1] Chen Y. Research on Investment Decision of University Fixed Assets Based on Big Data and Cloud Accounting[J]. Jiangsu Science \& Technology Information, 2015.

[2] Feng J. Cloud Accounting: The Transition of Accounting Information Model in the Big Data Background[C]// International Conference on Intelligent Transportation, Big Data and Smart City. IEEE, 2016:207-211.

[3] Asatiani A, Penttinen E. Managing the move to the cloud - analyzing the risks and opportunities of cloud-based accounting information systems[J]. Journal of Information Technology Teaching Cases, 2015, 5(1):27-34.

[4] Lu Y. The Characteristics and Its Application of Cloud Accounting under the Background of Big Data[C]// International Conference on Machinery, Materials and Computing Technology. 2017.

[5] Aleksandre Asatiani E P. Managing the move to the cloud |[ndash]| analyzing the risks and opportunities of cloud-based accounting information systems[J]. Journal of Information Technology Teaching Cases, 2015, 5(1):27-34.

[6] Sun Y, Business S O, University S. Research on the practice teaching reform of accounting information system based on cloud platform[J]. Laboratory Science, 2017.

[7] Quinn M J, Strauss E, Kristandl G. The effects of cloud technology on management accounting[J]. Financial Management, 2015, august:54-55.

[8] Liu H. Cloud-based billing, credential, and data sharing management system: US, US8984589[P]. 2015.

[9] Gao X, Yu C. A fuzzy-based recommendation system for cloud accounting service[C]// International Conference on Service Systems and Service Management. IEEE, 2016:1-6.

[10]Tzafilkou K, Nicolaos P, Dimitrios G. Accounting in the Cloud: Cloud-based Accounting Information Systems for Small and Medium sized Enterprises[C]// International Conference On Accounting and Finance. 2014.

[11]Cheng P, School A. The Influence of People, Data and System on the Quality of Accounting Information in Cloud Accounting Environment[J]. Journal of Chongqing University of Technology, 2016. 
[12]Zhang H. The Research Based on Big Data Management Accounting Model Building[J]. 2016, 4(4):228.

[13]Cai G M. Research on Impact of Medical People Based on Cloud SECI Accounting Theory[J]. Advanced Materials Research, 2014, 971-973:2368-2371. 